\title{
Efficacy and Adverse Events Associated With Use of OnabotulinumtoxinA for Treatment of Neurogenic Detrusor Overactivity: A Meta-Analysis
}

\author{
Hejia Yuan ${ }^{1, *}$, Yuanshan Cui ${ }^{1, *}$, Jitao $\mathrm{Wu}^{1}$, Peng Peng ${ }^{2}$, Xujie Sun ${ }^{3}$, Zhenli Gao ${ }^{1}$ \\ ${ }^{1}$ Department of Urology, The Affiliated Yantai Yuhuangding Hospital of Qingdao University, Yantai, China \\ ${ }^{2}$ Department of Pathology, Affiliated Hospital of Taishan Medical University, Taian, China \\ ${ }^{3}$ Department of Urology, Qingdao Chengyang People’s Hospital, Qingdao, China
}

Purpose: OnabotulinumtoxinA is used widely for the treatment of neurogenic detrusor overactivity. We conducted a systematic review and meta-analysis to assess its efficacy and safety for neurogenic detrusor overactivity treatment.

Methods: A systematic literature review was performed to identify all published randomized double-blind, placebo-controlled trials of onabotulinumtoxinA for neurogenic detrusor overactivity treatment. MEDLINE, Embase, and the CENTRAL were employed. Reference lists of retrieved studies were reviewed carefully.

Results: Six publications involving 871 patients, which compared onabotulinumtoxinA with a placebo were analyzed. Efficacy of onabotulinumtoxinA treatment was shown as a reduction of the mean number of urinary incontinence episodes per day (mean difference, $-1.41 ; 95 \%$ confidence interval $[\mathrm{CI}],-1.70$ to $-1.12 ; \mathrm{P}<0.00001$ ), maximum cystometric capacity (135.48; 95\% CI, 118.22-152.75; P <0.00001), and maximum detrusor pressure (-32.98; 95\% CI, -37.33 to $-28.62 ; \mathrm{P}<0.00001)$. Assessment of adverse events revealed that complications due to onabotulinumtoxinA injection were localized primarily to the urinary tract.

Conclusions: This meta-analysis suggests that onabotulinumtoxinA is an effective treatment for neurogenic detrusor overactivity with localized advent events.

Keywords: Neurogenic Detrusor Overactivity; OnabotulinumtoxinA; Meta-Analysis; Randomized Controlled Trial

- Conflict of Interest: No potential conflict of interest relevant to this article was reported.

\section{INTRODUCTION}

Neurogenic bladder dysfunction is associated with different neurological disease conditions and characterized by detrusor overactivity (DO), urinary incontinence (UI) and impaired quality of life (QoL). The International Continence Society defines DO as a urodynamic observation characterized by involuntary detrusor contractions during the filling phase, which may be spontaneous or provoked [1]. "Overactive bladder" is characterized as a symptom complex of urinary urgency with or without urge incontinence, but usually with high frequency of nocturia. "Neurogenic detrusor overactivity (NDO)" is a special type of overactive bladder associated with concurrent underlying neurological conditions such as injury to the spinal cord or multiple sclerosis [2]. DO frequently occurs in combination with detrusor sphincter dyssynergia, posing a threat to
Corresponding author: Zhenli Gao (iD http://orcid.org/0000-0002-2241-4242 Department of Urology, The Affiliated Yantai Yuhuangding Hospital of Qingdao University, NO. 20 East Yuhuangding Road, Yantai 264000, Shandong Province, China E-mail: gzlurology@163.com / Tel: +86-0535-6691999 / Fax: +86-0535-6695579.

${ }^{*}$ Hejia Yuan and Yuanshan Cui contributed equally to this study as co-first authors. Submitted: May 23, 2016 / Accepted after revision: August 2, 2016
This is an Open Access article distributed under the terms of the Creative Commons Attribution Non-Commercial License (http://creativecommons.org/licenses/by-nc/4.0/) which permits unrestricted non-commercial use, distribution, and reproduction in any medium, provided the original work is properly cited. 
the upper urinary tract [3].

Oral antimuscarinic agents are recommended as first-line treatment for NDO patients. These treatment regimens have been demonstrated to reduce the number of UI episodes, thereby improving urodynamic parameters and the QoL. However, long-term treatment with antimuscarinic agents may be suboptimal as a result of bothersome side effects and the drugs' loss of efficacy over time [4]. A more effective agent that can be delivered orally is not yet available. Hence, a new option that is effective and well tolerated for NDO treatment is needed.

Intradetrusor injection of onabotulinumtoxinA is a secondline treatment for NDO. It has been demonstrated to achieve profound inhibition of NDO and avoid high systemic levels at doses of $200 \mathrm{U}, 300 \mathrm{U}$, and $500 \mathrm{U}$ in several randomized placebo-controlled trials [5-9]. However, the optimal dose and adverse events associated with such treatment are controversial. Although Zhou et al. [10] and Zhang et al. [11] have compared the efficacy and adverse events of onabotulinumtoxinA treatment, Zhou et al. included only 4 publications and was not able to analyze the dose of 500 U. Patients with NDO often have severe symptoms, which means a high dose of injected onabotulinumtoxinA is warranted. Zhang et al. also neglected to study the risk of urinary retention (UR), which has since proven to be a substantial problem. We therefore conducted a meta-analysis to evaluate the efficacy and adverse events associated with onabotulinumtoxinA injection for NDO treatment, which might contribute to resolving such controversies.

\section{MATERIALS AND METHODS}

\section{Search Strategy}

A systematic search of the literature was undertaken using MEDLINE (1966 to May 2015), Embase (1993 to May 2015) and the CENTRAL databases to retrieve published randomized controlled trials (RCTs) investigating use of intradetrusor injections of onabotulinumtoxinA for NDO treatment. In addition, references of retrieved articles were screened. We searched the database by using combinations of the following terms: "onabotulinumtoxin $\mathrm{A}$, neurogenic detrusor overactivity, randomized controlled trial". A total of 6 publications were included in our analysis $[5-8,12,13]$.

\section{Inclusion Criteria and Selection of RCTs}

The following criteria were used to select RCTs: (1) OnabotulinumtoxinA treatment was included in the study. (2) Accurate

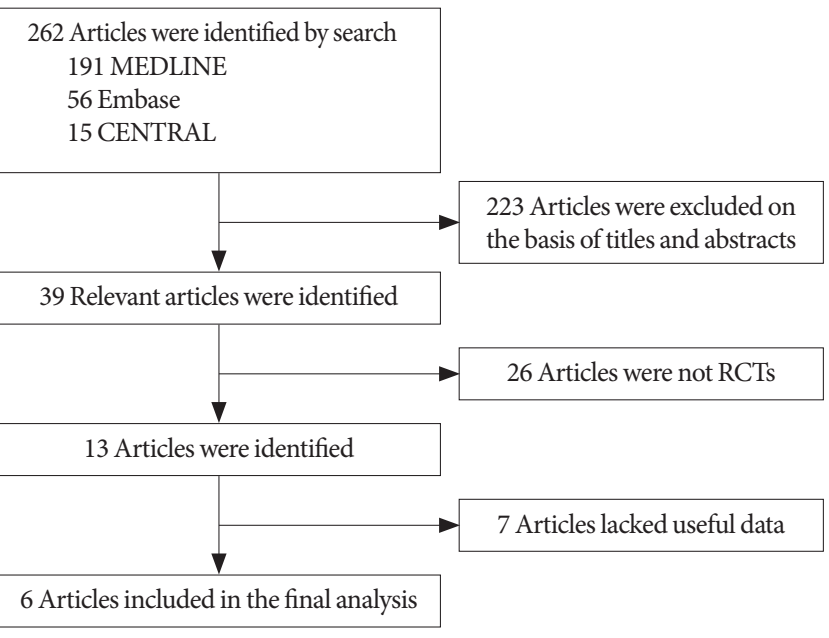

Fig. 1. A flow diagram of the study selection process. RCT, randomized controlled trial.

data were available for analysis (including the total number of subjects and the values of each index. (3) The full text of the study could be accessed. If the same study was published in different years or in different journals, only the most recent publication was used. If the same research team studied a group of subjects in different experiments, then each study was included. A flow diagram of the study selection process is presented in Fig. 1.

\section{Quality Assessment}

Two authors (HY and YC) of this study reviewed the selected publications. All retrieved RCTs were included in the metaanalysis regardless of the quality score. We assessed the quality of identified RCTs on the basis of generation of the allocation sequence, concealment of the allocation, blinding, reporting, and other factors according to the Cochrane library recommendations. The studies were then rated and assigned according to the guidelines published in the Cochrane Handbook for Systematic Reviews of Interventions (version 5.1.0.16). Based on the criteria for quality assessment, each study was evaluated using one of the following quality categories: A, quality criteria were met adequately, and the study was deemed to have a "low" risk of bias; $\mathrm{B}$, quality criteria was met only partially or were unclear, and the study was deemed to have a "moderate" risk of bias; $\mathrm{C}$, quality criteria were not met or not included, and the study was deemed to have a "high" risk of bias. Differences in option related to categorization were settled by discussion between HY and YC. 


\section{Data Extraction}

Each study was reviewed critically and the following information was collected: (1) name of the RCT, (2) characteristics of the study and patients, (3) study design and sample size, (4) injection dose, (5) country in which the study was carried out, (6) urodynamic parameters (mean number of UI episodes per week), maximum cytometric capacity (MCC) and maximum detrusor pressure (MDP) during the first involuntary detrusor contraction. The adverse events profile was assessed by the number of patients with urinary tract infections (UTIs) and UR. Data were retrieved by one person and evaluated by a second person.

\section{Statistical Analysis and Meta-analysis}

The meta-analysis was conducted using RevMan v.5.1.0 (Cochrane Collaboration, Oxford, UK). The mean number of UI episodes per week and the MCC and MDP during the first involuntary detrusor contraction were used for efficacy assessment. Change in the mean number of UI episodes per week was determined to be the main parameter. The proportion of UTIs and UR were used to reflect adverse events. The UTI proportion was determined to be the main parameter.

For continuous variables, the mean difference (MD) was calculated with a $95 \%$ confidence interval [CI]. The odds ratio (OR) with a $95 \% \mathrm{CI}$ was calculated for all dichotomous variables. We use the DerSimonian and Laird random-effects model to pool data across studies [14]. A fixed effects model was used if conspicuous heterogeneity was absent; otherwise, a random effects model was used. A subgroup analysis was carried out for some conditions.

\section{RESULTS}

\section{Characteristics of Individual Studies}

The database search yielded 262 articles. According to the inclusion criteria described above, 6 RCTs that compared onabotulinumtoxinA with placebo were included in the analysis. Two hundred twenty-three articles were excluded after reading their titles and abstracts, 26 articles were not RCTs, and 7 articles lacked useful data. Baseline characteristics of the selected studies are listed in Table 1. All patients were administered onabotulinumtoxinA by detrusor injections ( $1 \mathrm{~mL}$ each) avoiding trigone and evaluated at weeks 6 after treatment.

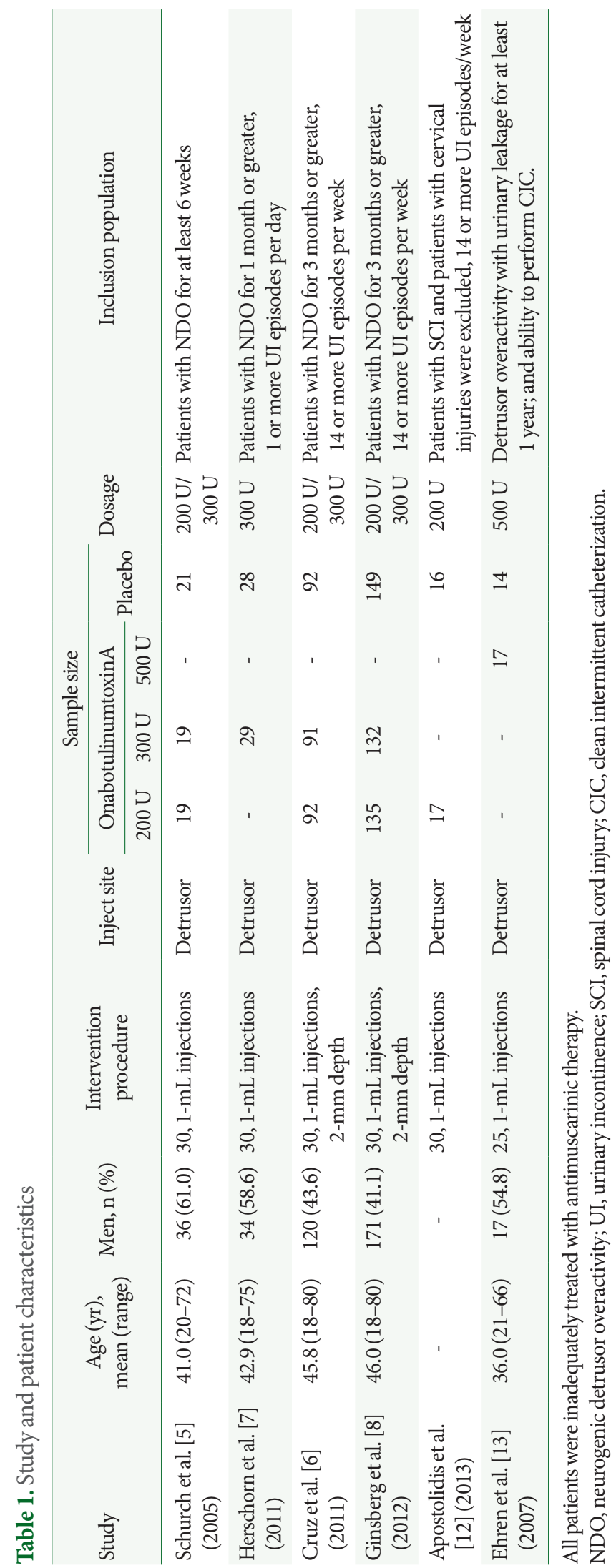

www.einj.org 
Table 2. Quality assessment of individual study

\begin{tabular}{|c|c|c|c|c|c|c|}
\hline Study & $\begin{array}{c}\text { Allocation sequence } \\
\text { generation }\end{array}$ & $\begin{array}{c}\text { Allocation } \\
\text { concealment }\end{array}$ & Blinding & Reporting bias & $\begin{array}{l}\text { Intention-to- } \\
\text { treat analysis }\end{array}$ & Other bias \\
\hline Schurch et al. [5] (2005) & $\mathrm{A}$ & A & A & A & Yes & $0 \%$ of dropout rate \\
\hline Herschorn et al. [7] (2011) & A & A & A & A & Yes & $10 \%$ of dropout rate \\
\hline Cruz et al. [6] (2011) & A & A & A & A & Yes & $1.4 \%$ of dropout rate \\
\hline Ginsberg et al. [8] (2012) & $\mathrm{A}$ & A & A & A & Yes & $2.2 \%$ of dropout rate \\
\hline Apostolidis et al. [12] (2013) & A & A & A & A & Yes & $6 \%$ of dropout rate \\
\hline Ehren et al. [13] (2007) & A & A & A & A & No & $0 \%$ of dropout rate \\
\hline
\end{tabular}

A, All quality criteria met (adequate): low risk of bias.
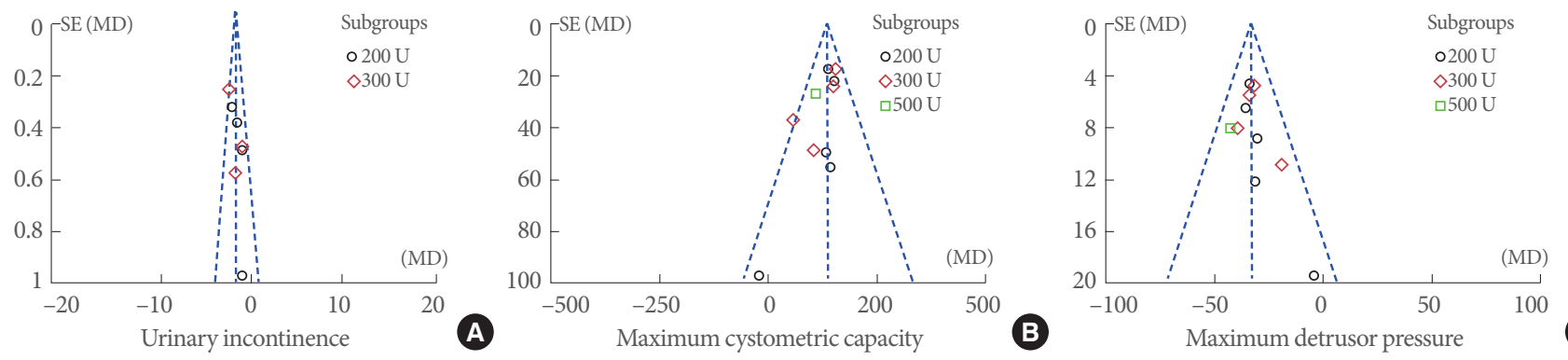

C

Fig. 2. Funnel plot of the studies represented in our meta-analysis. SE, standard error; MD, mean difference.

\section{Quality of the Individual Studies}

All 6 RCTs were double blinded, and all elaborated on their randomization processes. We used a powerful calculation to determine the optimal sample size of retrieved studies. The results of quality assessments are listed in Table 2.

\section{Publication Bias}

Funnel plots were used to produce a qualitative estimation of publication bias of the studies. All values of UI (Fig. 2A), MCC (Fig. 2B), and MDP (Fig. 2C) lie within the scope of the funnel plots and were evenly distributed on both sides of the central lines, which suggests there is no evidence of bias.

\section{Efficacy}

\section{Mean number of Ul episodes per day}

Five RCTs representing 840 participants (534 in the onabotulinumtoxinA group and 306 in the control group) were included on the change of the mean number of UI episodes per day (Fig. 3A). The pooled overall MD of UI episodes per day for the onabotulinumtoxinA group versus the placebo group was -1.41 (95\% CI, -1.70 to -1.12 ). There was a statistically significant difference between the 2 groups. The heterogeneity test (Cochrane's $\mathrm{Q}$ statistic $\mathrm{P}$-value) result was $\mathrm{P}=0.14$ and the Higgins'
$\mathrm{I}^{2}$ value was $36 \%$. For evaluation of dose factors that were associated with improvement of NDO, we also conducted subgroup analysis. The MD changes of UI episodes per day improvement were -1.38 (95\% CI, -1.83 to -0.94$)$ for $200 \mathrm{U}$ and $-1.42(95 \%$ CI, -1.81 to -1.04 ) for 300 U. OnabotulinumtoxinA at $200 \mathrm{U}$ and $300 \mathrm{U}$ showed superior efficacy in reducing the mean number of UI episodes per day compared with placebo. Then, we further identified the differentiation between $200 \mathrm{U}$ and $300 \mathrm{U}$ of onabotulinumtoxinA using a meta-regression method using residual maximum likelihood (Table 3 ). No obvious dose-dependent differences were found between the groups $(\mathrm{P}=0.974)$.

\section{Maximum cystometric capacity}

Six RCTs representing 871 participants (551 in the onabotulinumtoxinA group and 320 in the control group) were included on improvement of MCC (Fig. 3B). The pooled overall MD of MCC for the onabotulinumtoxinA group versus the placebo group was 135.48 (95\% CI, 118.22-152.75). There was a statistically significant difference between the 2 groups. The heterogeneity test (Cochrane's $\mathrm{Q}$ statistics $\mathrm{P}$-value) result was $\mathrm{P}=0.51$ and the Higgins' $\mathrm{I}^{2}$ value was $0 \%$. For evaluation of dose factors that impact improvement of NDO, we also conducted subgroup analysis. The MD changes of MCC improvement were 


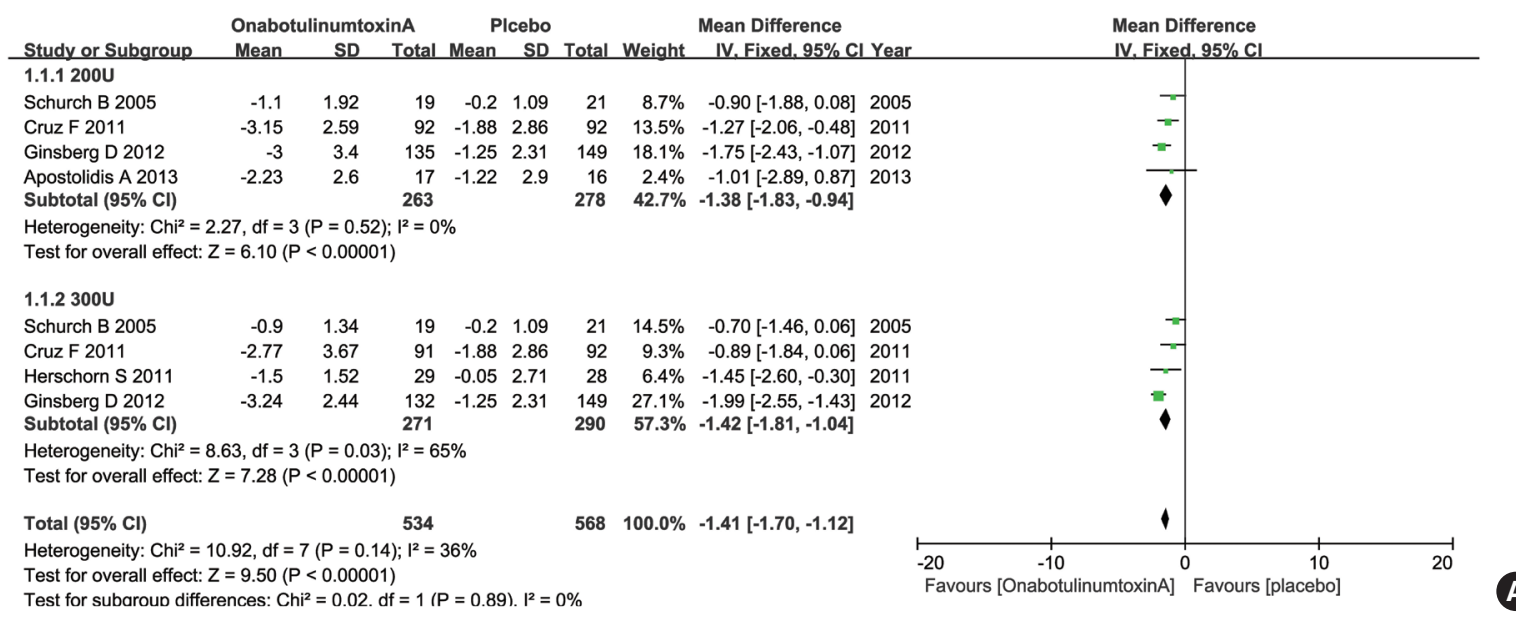

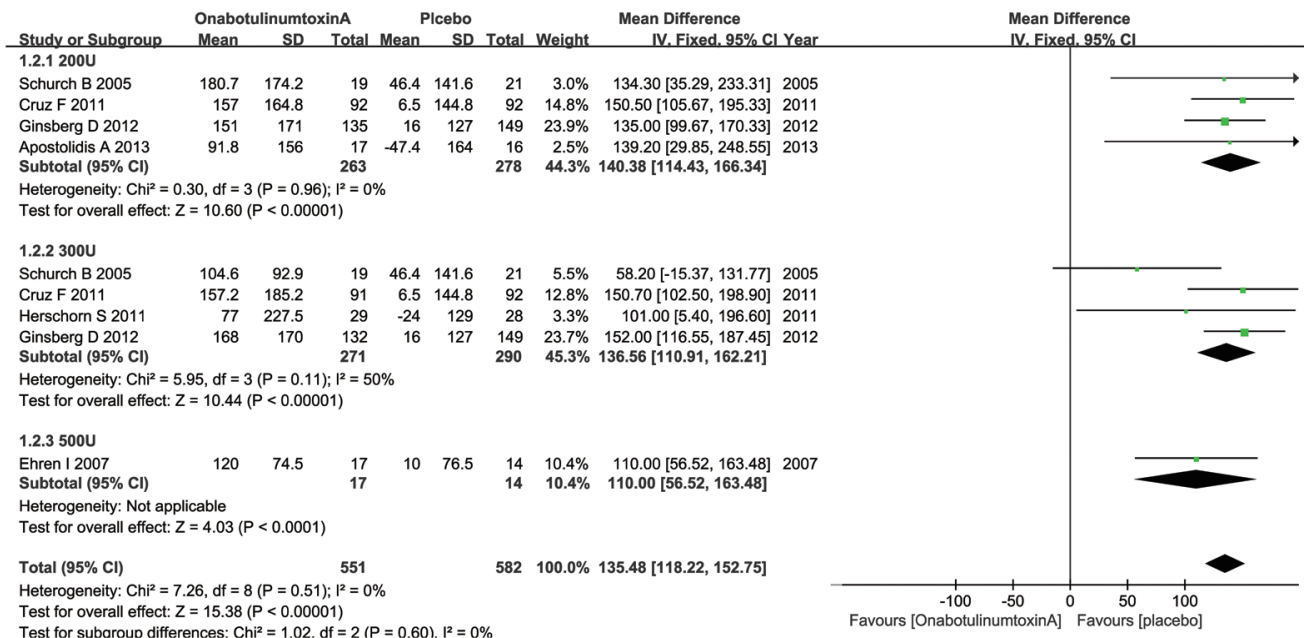

Test for subaroun differences: $\mathrm{Ch}^{\mathrm{i}}=1.02 . \mathrm{df}=2(P=0.60) . \mathrm{I}^{2}=0 \%$

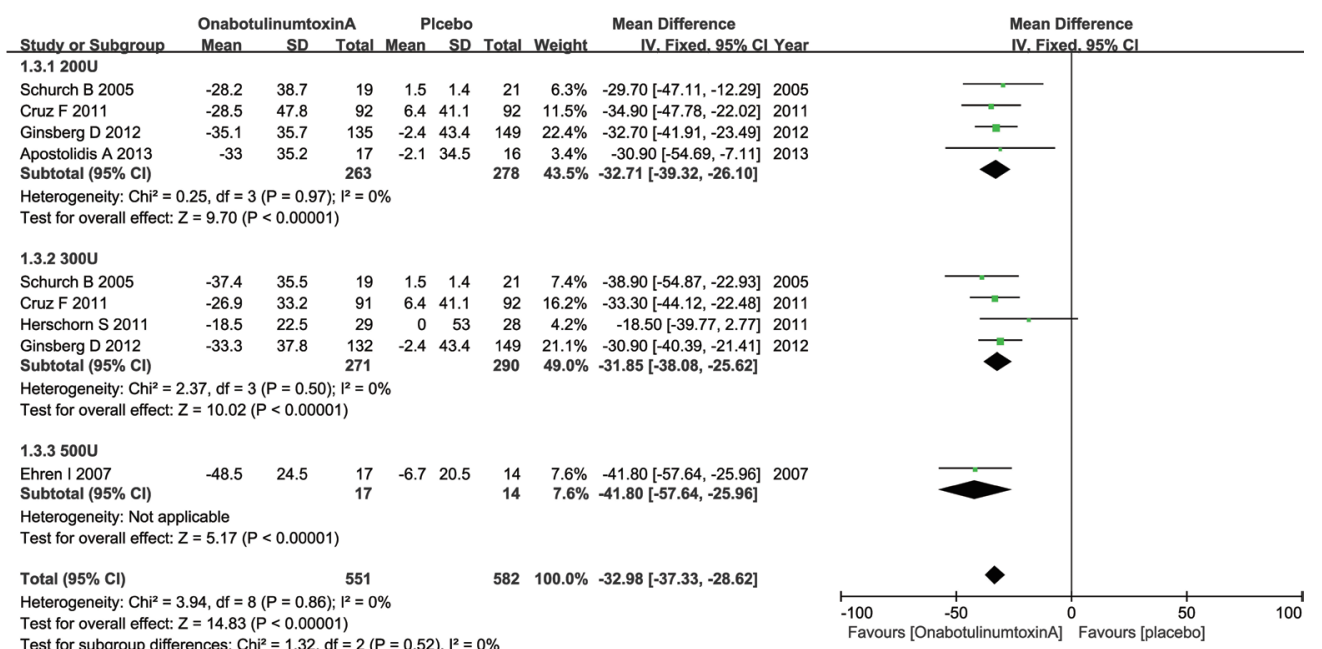

Fig. 3. Forest plots showing changes in the mean number of urinary incontinence per day (A), changes in maximum cystometric capacity (B), and changes in maximum detrusor pressure during first involuntary detrusor contraction (C). CI, confidence interval; SD, standard deviation; IV, inverse variance; $\mathrm{df}$, degrees of freedom. 
Table 3. Effects of moderators for urinary incontinence

\begin{tabular}{|c|c|c|c|c|c|c|}
\hline \multirow{2}{*}{ Variable } & \multicolumn{6}{|c|}{ Urinary incontinence } \\
\hline & $k$ & Regression coefficient & $\mathrm{MD}$ & SE & $95 \% \mathrm{CI}$ & P-value ${ }^{a)}$ \\
\hline No. of patients & 8 & -0.004 & - & 0.001 & -0.007 to -0.001 & 0.029 \\
\hline Dosage & & & & & & 0.974 \\
\hline $200 \mathrm{U}$ & 4 & - & -1.394 & - & -1.832 to -0.956 & \\
\hline $300 \mathrm{U}$ & 4 & - & -1.425 & - & -1.808 to -1.041 & \\
\hline
\end{tabular}

$k$, number of observations; $\mathrm{MD}$, mean difference; SE, standard error; CI, confidence interval.

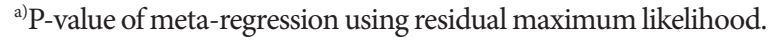

\begin{tabular}{|c|c|c|c|c|c|c|c|c|}
\hline \multirow[b]{2}{*}{ Study or Subgroup } & OnabotulinumtoxinA & \multicolumn{2}{|c|}{ Plcebo } & \multirow[b]{2}{*}{ Weight } & \multirow{2}{*}{$\begin{array}{l}\text { Odds Ratio } \\
\text { M-H, Fixed, } 95 \% \text { Cl Year }\end{array}$} & \multirow{2}{*}{\multicolumn{3}{|c|}{$\begin{array}{c}\text { Odds Ratio } \\
\text { M-H, Fixed. } 95 \% \mathrm{Cl}\end{array}$}} \\
\hline & Events & Events & Total & & & & & \\
\hline Schurch B 2005 & 38 & 3 & 21 & $5.2 \%$ & $2.14[0.52,8.86] 2005$ & & & \\
\hline Cruz F 2011 & 183 & 20 & 92 & $32.6 \%$ & $1.71[0.95,3.07] 2011$ & & & \\
\hline Herschorn S 2011 & 29 & 16 & 28 & $13.2 \%$ & $0.92[0.32,2.63] 2011$ & & & \\
\hline Ginsberg D 2012 & 267 & 26 & 149 & $43.6 \%$ & $1.81[1.10,2.99] 2012$ & & $\rightarrow$ & \\
\hline Apostolidis A 2013 & 17 & 7 & 16 & $5.4 \%$ & $1.84[0.46,7.31] 2013$ & & & \\
\hline Total $(95 \% \mathrm{Cl})$ & 534 & & 306 & $100.0 \%$ & $1.68[1.20,2.35]$ & & & \\
\hline Total events & 169 & 72 & & & & & & \\
\hline \multirow{2}{*}{\multicolumn{6}{|c|}{$\begin{array}{l}\text { Heterogeneity: } \mathrm{Chi}^{2}=1.48, \mathrm{df}=4(P=0.83) ; \mathrm{I}^{2}=0 \% \\
\text { Test for overall effect: } Z=3.05(P=0.002)\end{array}$}} & 0.01 & 10 & 100 \\
\hline & & & & & & Favours [OnabotulinumtoxinA] & Favours [placebo] & \\
\hline & Onabotulinumtoxin $A$ & Plceb & & & Odds Ratio & Odds & Ratio & \\
\hline Study or Subgroup & Events Total & Events & Total & Weight & M-H, Fixed. $95 \% \mathrm{CI}$ Year & M-H,Fixe & ed. $95 \% \mathrm{Cl}$ & \\
\hline Cruz F 2011 & 183 & 3 & 92 & $30.1 \%$ & $9.96[3.01,33.01] 2011$ & & & \\
\hline Herschorn S 2011 & 29 & 2 & 28 & $16.9 \%$ & $2.71[0.48,15.29] 2011$ & & & \\
\hline Ginsberg D 2012 & 267 & 5 & 149 & $53.0 \%$ & $6.31[2.45,16.24] 2012$ & & & \\
\hline Total $(95 \% \mathrm{Cl})$ & 479 & & 269 & $100.0 \%$ & $6.80[3.46,13.35]$ & & & \\
\hline Total events & 99 & 10 & & & & & & \\
\hline $\begin{array}{l}\text { Heterogeneity: } \mathrm{Chi}^{2}= \\
\text { Test for overall effect: }\end{array}$ & $\begin{array}{l}1.50, d f=2(P=0.47) ; I^{2}= \\
Z=5.57(P<0.00001)\end{array}$ & $0 \%$ & & & & 0.01 & 10 & 100 \\
\hline
\end{tabular}

Fig. 4. Forest plots showing changes in urinary tract infections (A) and changes in urinary retention (B). M-H, Mantel-Haenszel; CI, confidence interval; df, degrees of freedom.

140.38 (95\% CI, 114.43-166.34) for 200 U, 136.56 (95\% CI, $110.91-162.21)$ for $300 \mathrm{U}$, and 110.00 (95\% CI, 56.52-163.48) for $500 \mathrm{U}$. These results suggested that onabotulinumtoxinA injection caused a significant increase in the MCC regardless of dose.

\section{MDP during first involuntary detrusor contraction}

Six RCTs representing 871 participants (551 in the onabotulinumtoxinA group and 320 in the control group) were included on MDP improvement during the first involuntary detrusor contraction (Fig. 3C). The pooled overall MD of MDP during the first involuntary detrusor contraction for the onabotulinumtoxinA group versus the placebo group was -32.98 (95\% CI, -37.33 to -28.62$)$. There was a statistically significant difference between the 2 groups. The heterogeneity test (Cochrane's Q statistic P-value) result was $\mathrm{P}=0.86$ and the Higgins' $\mathrm{I}^{2}$ value was
$0 \%$. For evaluation of dose factors that impact improvement of NDO, we also conducted subgroup analysis. The MD changes of MDP during the first involuntary detrusor contraction improvement were -32.71 (95\% CI, -39.32 to -26.10 ) for $200 \mathrm{U},-31.85$ (95\% CI, -38.08 to -25.62 ) for $300 \mathrm{U}$, and -41.80 (95\% CI, -57.64 to -25.96$)$ for $500 \mathrm{U}$. These results suggested that onabotulinumtoxinA at $200 \mathrm{U}, 300 \mathrm{U}$, and $500 \mathrm{U}$ successfully reduced MDP during the first involuntary detrusor contraction compared with the placebo.

\section{Adverse Events \\ UTI and UR}

For the UTI analysis, 5 RCTs representing 840 participants (534 in the onabotulinumtoxinA group and 306 in the control group) were included (Fig. 4A). The pooled overall OR of UTIs for the onabotulinumtoxinA group versus the placebo group 
was 1.68 (95\% CI, 1.20-2.35). There was a statistically significant difference between the 2 groups. The heterogeneity test (Cochrane's $\mathrm{Q}$ statistic $\mathrm{P}$-value) result was $\mathrm{P}=0.83$ and the Higgins' $\mathrm{I}^{2}$ value was $0 \%$. For the UR analysis, 3 of the RCTs representing 748 participants (479 in the onabotulinumtoxinA group and 269 in the control group) were included (Fig. 4B). The pooled overall OR of UR for the onabotulinumtoxinA group versus the placebo group was 6.80 (95\% CI, 3.46-13.35). There was a statistically significant difference between the 2 groups. The heterogeneity test (Cochrane's Q statistic P-value) result was $\mathrm{P}=0.47$ and the Higgins' $\mathrm{I}^{2}$ value was $0 \%$. The results suggested that onabotulinumtoxin $\mathrm{A}$ was regularly associated with complications localized primarily to the urinary tract.

\section{DISCUSSION}

The primary goals of NDO treatment are protection of the upper urinary tract by reducing the bladder pressure and UI [3]. Intradetrusor injection of onabotulinumtoxinA results in a decreased risk of vesicoureteral reflux by reducing the proportion of UI and MDP. Therefore, damages to the upper urinary tract and kidney can be averted [15]. Moreover, an increase in bladder capacity (as measured by MCC) means that the bladder can accommodate a larger volume of urine without involuntary losses [16-19].

OnabotulinumtoxinA was injected directly into the detrusor in all studies. Most studies reported sparing the bladder trigone, whereas 2 involved studies reported the injection of onabotulinumtoxinA into the bladder trigone without reporting severe complications [20,21]. Moreover, evidence suggests that superior efficacy was obtained after combining injection into the detrusor and bladder trigone compared with intradetrusor injection alone [22]. A recent study carried out by Hoag et al. [23] showed that, intravesical onabotulinumtoxinA injection is feasible treatment for overactive bladder in orthotopic neobladders. Further studies are needed to determine whether single detrusor injection or combination with trigone injections increases onabotulinumtoxin A efficacy.

The analysis of pooled data demonstrated that onabotulinumtoxinA significantly reduced the daily frequency of UI and MDP during first involuntary detrusor contraction, and improved MCC in patients with UI due to NDO. These results are consistent with previous studies on onabotulinumtoxin A injection [16,21]. Schurch et al. [5] found that onabotulinumtoxinA $200 \mathrm{U}$ and $300 \mathrm{U}$ led to a considerable reduction in UI episodes, and improved urodynamic parameters and QoL compared with placebo. Cruz et al. [6] found no obvious dosedependent differences between the groups receiving $200 \mathrm{U}$ and $300 \mathrm{U}$ onabotulinumtoxinA injections with respect to continence. Ehren et al. [13] noted that patients administered the maximum dose of tolterodine tablets would probably have benefited from a higher dose of onabotulinumtoxinA. Starting treatment with $500 \mathrm{U}$ onabotulinumtoxin A may be a good strategy to allow rescue medication. Therefore, an ongoing effort to clarify the optimal dose of onabotulinumtoxinA injection is needed.

Interestingly, Ginsberg et al. [24] found that improvements in UI, urodynamic parameters, and duration of effects were independent of the effects of antimuscarinic dugs after onabotulinumtoxinA treatment. This phenomenon could be explained by the mechanism of onabotulinumtoxinA. Data from studies in experimental animals $[25,26]$ suggest that onabotulinumtoxinA blocks release of different neuropeptides and neurotransmitters into the neuromuscular junction, and acts on both motor and sensory pathways [27]. Therefore, onabotulinumtoxinA may be more effective in preventing activation of muscarinic receptors compared with antimuscarinic drugs [28]. When the effects of onabotulinumtoxinA are observed in clinical practice, withdrawal of the concomitant antimuscarinic agent is recommended. Readministration of antimuscarinic agents is recommended as soon as the effects of onabotulinumtoxinA decrease [24].

We noticed a comparable adverse events profile across treatment groups. The occurrence of UTIs in the NDO population is common, particularly in patients who have postvoid residual and are using clean intermittent catheterization (CIC) $[3,29,30]$. A recent study of patients with NDO showed that UTIs were the most commonly diagnosed condition after onabotulinumtoxinA injection, impacting $29 \%$ to $36 \%$ of patients [31]. In addition, the UR proportion increased significantly in the onabotulinumtoxinA group compared with placebo. Patients who did not use CIC at baseline were more likely than other patients to be associated with CIC initiation [32]. To evaluate whether CIC initiation might possibly affect the QoL score, Chancellor et al. [19] examined the changes in patients using CIC before treatment and in those who did not use CIC before, but initiated CIC after. Comparisons showed no significant difference. Ginsberg et al. [8] found that improvements in the QoL score were similar in patients with or without CIC. Khan et al. [17] revealed that the satisfaction with treatment of multiple sclero- 
sis patients appeared to be independent of CIC initiation. These findings suggested that initiation of CIC has little influence on patients' perception of benefit from onabotulinumtoxinA treatment. We therefore consider UR induced by onabotulinumtoxinA injection to be less of a problem [29]. Since UR is a risk of onabotulinumtoxinA treatment, patients not undergoing CIC before should be based only on careful individual evaluation of the benefits and risks. Overall, onabotulinumtoxinA treatment was effective with adverse events localized to the urinary tract.

All studies included in this meta-analysis were selected from randomized double-blind, placebo-controlled trials. The quality of the individual study in the meta-analysis was adapted to the quality-assessment scale we developed. Nevertheless, our metaanalysis had limitations. First, the number of studies included was limited: only 6 RCTs assessing the efficacy and adverse events of onabotulinumtoxinA injection were included. Second, there might be some publication bias, search bias, or selection bias. Third, assessment of the longer-term safety and efficacy of onabotulinumtoxinA injection cannot be obtained from a single meta-analysis. Therefore, more high-quality RCTs with larger patient cohorts are needed to ascertain the efficacy and safety of NDO treatment.

In conclusion, our meta-analysis suggests that onabotulinumtoxinA injection is an effective treatment for NDO symptoms with adverse events localized primarily to the urinary tract.

\section{REFERENCES}

1. Abrams P, Cardozo L, Fall M, Griffiths D, Rosier P, Ulmsten U, et al. The standardisation of terminology in lower urinary tract function: report from the standardisation sub-committee of the International Continence Society. Urology 2003;61:37-49.

2. Abrams P, Cardozo L, Fall M, Griffiths D, Rosier P, Ulmsten U, et al. The standardisation of terminology of lower urinary tract function: report from the Standardisation Sub-committee of the International Continence Society. Neurourol Urodyn 2002;21:167-78.

3. Stöhrer M, Blok B, Castro-Diaz D, Chartier-Kastler E, Del Popolo $\mathrm{G}$, Kramer G, et al. EAU guidelines on neurogenic lower urinary tract dysfunction. Eur Urol 2009;56:81-8.

4. del Popolo G, Mencarini M, Nelli F, Lazzeri M. Controversy over the pharmacological treatments of storage symptoms in spinal cord injury patients: a literature overview. Spinal Cord 2012;50:8-13.

5. Schurch B, de Sèze M, Denys P, Chartier-Kastler E, Haab F, Everaert $\mathrm{K}$, et al. Botulinum toxin type $\mathrm{a}$ is a safe and effective treatment for neurogenic urinary incontinence: results of a single treatment, randomized, placebo controlled 6-month study. J Urol 2005;174: 196-200.

6. Cruz F, Herschorn S, Aliotta P, Brin M, Thompson C, Lam W, et al. Efficacy and safety of onabotulinumtoxinA in patients with urinary incontinence due to neurogenic detrusor overactivity: a randomised, double-blind, placebo-controlled trial. Eur Urol 2011;60: 742-50.

7. Herschorn S, Gajewski J, Ethans K, Corcos J, Carlson K, Bailly G, et al. Efficacy of botulinum toxin A injection for neurogenic detrusor overactivity and urinary incontinence: a randomized, double-blind trial. J Urol 2011;185:2229-35.

8. Ginsberg D, Gousse A, Keppenne V, Sievert KD, Thompson C, Lam W, et al. Phase 3 efficacy and tolerability study of onabotulinumtoxinA for urinary incontinence from neurogenic detrusor overactivity. J Urol 2012;187:2131-9.

9. Sussman D, Patel V, Del Popolo G, Lam W, Globe D, Pommerville P. Treatment satisfaction and improvement in health-related quality of life with onabotulinumtoxinA in patients with urinary incontinence due to neurogenic detrusor overactivity. Neurourol Urodyn 2013;32:242-9.

10. Zhou X, Yan HL, Cui YS, Zong HT, Zhang Y. Efficacy and safety of onabotulinumtoxin A in treating neurogenic detrusor overactivity: a systematic review and meta-analysis. Chin Med J (Engl) 2015; 128:963-8.

11. Zhang R, Xu Y, Yang S, Liang H, Zhang Y, Liu Y. OnabotulinumtoxinA for neurogenic detrusor overactivity and dose differences: a systematic review. Int Braz J Urol 2015;41:207-19.

12. Apostolidis A, Thompson C, Yan X, Mourad S. An exploratory, placebo-controlled, dose-response study of the efficacy and safety of onabotulinumtoxinA in spinal cord injury patients with urinary incontinence due to neurogenic detrusor overactivity. World J Urol 2013;31:1469-74.

13. Ehren I, Volz D, Farrelly E, Berglund L, Brundin L, Hultling C, et al. Efficacy and impact of botulinum toxin A on quality of life in patients with neurogenic detrusor overactivity: a randomised, placebo-controlled, double-blind study. Scand J Urol Nephrol 2007;41: 335-40.

14. DerSimonian R, Laird N. Meta-analysis in clinical trials. Control Clin Trials 1986;7:177-88.

15. Foley SJ, McFarlane JP, Shah PJ. Vesico-ureteric reflux in adult patients with spinal injury. Br J Urol 1997;79:888-91.

16. Wefer B, Ehlken B, Bremer J, Burgdörfer H, Domurath B, Hampel $\mathrm{C}$, et al. Treatment outcomes and resource use of patients with neurogenic detrusor overactivity receiving botulinum toxin A (BO- 
TOX) therapy in Germany. World J Urol 2010;28:385-90.

17. Khan S, Game X, Kalsi V, Gonzales G, Panicker J, Elneil S, et al. Long-term effect on quality of life of repeat detrusor injections of botulinum neurotoxin-A for detrusor overactivity in patients with multiple sclerosis. J Urol 2011;185:1344-9.

18. Schurch B, Stöhrer M, Kramer G, Schmid DM, Gaul G, Hauri D. Botulinum-A toxin for treating detrusor hyperreflexia in spinal cord injured patients: a new alternative to anticholinergic drugs? Preliminary results. J Urol 2000;164(3 Pt 1):692-7.

19. Chancellor MB, Patel V, Leng WW, Shenot PJ, Lam W, Globe DR, et al. OnabotulinumtoxinA improves quality of life in patients with neurogenic detrusor overactivity. Neurology 2013;81:841-8.

20. Giannantoni A, Mearini E, Di Stasi SM, Costantini E, Zucchi A, Mearini $L$, et al. New therapeutic options for refractory neurogenic detrusor overactivity. Minerva Urol Nefrol 2004;56:79-87.

21. Reitz A, Stöhrer M, Kramer G, Del Popolo G, Chartier-Kastler E, Pannek J, et al. European experience of 200 cases treated with botulinum-A toxin injections into the detrusor muscle for urinary incontinence due to neurogenic detrusor overactivity. Eur Urol 2004; 45:510-5.

22. Abdel-Meguid TA. Botulinum toxin-A injections into neurogenic overactive bladder--to include or exclude the trigone? A prospective, randomized, controlled trial. J Urol 2010;184:2423-8.

23. Hoag N, Tse V, Wang A, Chung E, Gani J. Intravesical OnabotulinumtoxinA Injection for Overactive Orthotopic Ileal Neobladder: Feasibility and Efficacy. Int Neurourol J 2016;20:81-5.

24. Ginsberg D, Cruz F, Herschorn S, Gousse A, Keppenne V, Aliotta P, et al. OnabotulinumtoxinA is effective in patients with urinary in- continence due to neurogenic detrusor overactivity [corrected] regardless of concomitant anticholinergic use or neurologic etiology. Adv Ther 2013;30:819-33.

25. Dolly O. Synaptic transmission: inhibition of neurotransmitter release by botulinum toxins. Headache 2003;43 Suppl 1:S16-24.

26. Ikeda Y, Zabbarova IV, Birder LA, de Groat WC, McCarthy CJ, Hanna-Mitchell AT, et al. Botulinum neurotoxin serotype A suppresses neurotransmitter release from afferent as well as efferent nerves in the urinary bladder. Eur Urol 2012;62:1157-64.

27. Apostolidis A, Dasgupta P, Fowler CJ. Proposed mechanism for the efficacy of injected botulinum toxin in the treatment of human detrusor overactivity. Eur Urol 2006;49:644-50.

28. Finney SM, Andersson KE, Gillespie JI, Stewart LH. Antimuscarinic drugs in detrusor overactivity and the overactive bladder syndrome: motor or sensory actions? BJU Int 2006;98:503-7.

29. De Laet K, Wyndaele JJ. Adverse events after botulinum A toxin injection for neurogenic voiding disorders. Spinal Cord 2005;43: 397-9.

30. Sauerwein D. Urinary tract infection in patients with neurogenic bladder dysfunction. Int J Antimicrob Agents 2002;19:592-7.

31. Manack A, Motsko SP, Haag-Molkenteller C, Dmochowski RR, Goehring EL Jr, Nguyen-Khoa BA, et al. Epidemiology and healthcare utilization of neurogenic bladder patients in a US claims database. Neurourol Urodyn 2011;30:395-401.

32. Kessler TM, Khan S, Panicker J, Roosen A, Elneil S, Fowler CJ. Clean intermittent self-catheterization after botulinum neurotoxin type A injections: short-term effect on quality of life. Obstet Gynecol 2009;113:1046-51. 